\title{
Low friction in self-mated silicon carbide tribosystem using nanodiamond as lubricating additive in water
}

\author{
Xudong WANG ${ }^{1,2}$, Hirotsuna SATO ${ }^{2,3}$, Koshi ADACHI ${ }^{2, *}$ \\ ${ }^{1}$ Université Paris-Saclay, UVSQ, LISV, Vélizy-Villacoublay 78124, France \\ ${ }^{2}$ Department of Mechanical Systems Engineering, Graduate School of Engineering, Tohoku University, 6-6-01, Aramaki-aza- \\ Aoba, Aoba-ku, Sendai 980-8579, Japan \\ ${ }^{3}$ Hino Motors, Ltd., 3-1-1, Hino-dai, Hino-shi, Tokyo 191-8660, Japan
}

Received: 27 February 2020 / Revised: 18 May 2020 / Accepted: 28 June 2020

(C) The author(s) 2020.

\begin{abstract}
Nanodiamond particles (NDPs) have been considered as a potential lubricant additive to various tribological applications, such as water lubrication systems. In this study, the tribological properties of silicon carbide $(\mathrm{SiC})$ lubricated by NDPs dispersed in water are investigated utilizing the ball-on-disk tribometer. It is found that the slight addition of NDP to water (i.e., $0.001 \mathrm{wt} \%$ ) can distinctly accelerate the running-in process, which is necessary to achieve a friction coefficient $(\mu)$ as low as 0.01 . This study also discusses two NDP functional terminations-hydroxyl and carboxyl. It is demonstrated that the use of carboxyl-terminated NDP over a wide range of concentration (0.001-1 wt\%) yields a low friction force. In contrast, the ideal effective concentration of hydroxyl-terminated NDP is considerably limited because agglomeration in this material is more probable to occur than in the former. Meanwhile, when utilizing NDPs, the input friction energy ( $P_{\text {in }}$, defined as the product of sliding speed and applied load) is found to have an essential function. Several sliding tests were implemented at various $P_{\text {in }}$ values $(50-1,500 \mathrm{~mW})$ using carboxyl-terminated water-dispersed NDPs. It was observed that the $\mu$ and wear decreased with increasing $P_{\text {in }}$ when $200 \mathrm{~mW}<P_{\text {in }}<1,500 \mathrm{~mW}$. However, when $P_{\text {in }}<200 \mathrm{~mW}$, low friction with high wear occurs compared with the resulting friction and wear when pure water is used.
\end{abstract}

Keywords: nanodiamond particle; silicon carbide ( $\mathrm{SiC})$; lubrication; termination groups; running-in; driving energy

\section{Introduction}

Since the 1980s, low viscosity and environmentally friendly water has been investigated as a potential lubricant to improve the tribological performance of ceramics [1-6]. Silicon carbide (SiC), which is one of the most widely used antifriction materials, is a typical representative ceramic. Chen et al. [7] have reported that the sliding friction in self-mated $\mathrm{SiC}$ gradually decreases in the presence of water. In other words, running-in is required to achieve low friction in water. It has also been demonstrated that the rougher the SiC surface, the longer the required running-in period [8]. The effect of running-in is explained from the viewpoint of wear, and it has been recognized that the chemical wear of $\mathrm{SiC}$ in water is extremely important. However, the hydrothermal oxidation of $\mathrm{SiC}$ requires high pressure and high temperature. The chemical reactions indicate that the formation of amorphous $\mathrm{SiO}_{2}$ occurs under various experimental conditions [9-13]. Lin and Kao [14] have studied the polishing of $\mathrm{SiC}$ at

* Corresponding author: Koshi ADACHI, E-mail: koshi.adachi.e4@tohoku.ac.jp 
$30{ }^{\circ} \mathrm{C}$ with the tribochemical reaction mechanism, and subsequently proposed Eq. (1) based on the formation of carbon debris. Nevertheless, a long running-in sliding distance is necessary. Moreover, the low load-carrying capacity because of the low viscosity of water is a critical problem, i.e., the low friction afforded by water lubrication is only achieved under limited conditions.

$$
\mathrm{SiC}+2 \mathrm{H}_{2} \mathrm{O} \rightarrow \mathrm{SiO}_{2}+\mathrm{C}+2 \mathrm{H}_{2}
$$

Adachi [15] indicated that the load-carrying capacity of $\mathrm{SiC} / \mathrm{SiC}$ in water increases with the running-in load, which makes the surface more hydrophilic. This newly self-formed surface, i.e., a nanointerface with high hydrophilicity, is among the requirements for improving the load-carrying capacity afforded by water lubrication. A feasible approach for enhancing the tribochemical reactions and running-in effect is surface texturing $[15,16]$. Wang et al. [17-20] conducted a series of interrelated studies on the self-mated $\mathrm{SiC}$ water lubrication system and found that the load-carrying capacity remarkably improved. Another promising method to create a low frictional interface is the introduction of additives to water, which is easier to implement than surface texturing. Considered as ideal additives, nanocarbons have considerably attracted the interest of researchers. Some recent studies have also discovered that in various engineering applications, materials from the graphene family are among the promising candidates for lubricants and lubricating additives [21, 22]. As reported by Ge et al. [23], macroscale superlubricity (friction coefficient, $\mu=0.0037$ ) at the $\mathrm{Si}_{3} \mathrm{~N}_{4}-\mathrm{SiO}_{2}$ interface is achieved when grapheneoxide nanoflakes and ethanediol are used as lubricants. Thereafter, they found that the liquid-superlubricity state with $\mu=0.005$ for $\mathrm{Si}_{3} \mathrm{~N}_{4}$-sapphire tribopairs can be achieved through the combination of grapheneoxide nanosheets and ionic liquid [24]. As reported by $\mathrm{Wu}$ et al. [25], a low friction coefficient and minuscule wear track can be obtained in the $\mathrm{Si}_{3} \mathrm{~N}_{4} / \mathrm{Si}$ tribosystem because of the synergistic effect between graphene oxide and nanodiamond as lubrication additives in water. The detonation nanodiamond particle (NDP) is another candidate that has attracted attention. Its effect on various mechanisms, such as nano-bearing [26], substrate embedding
[27, 28], and nanoscale water carrying [29] or polishing [30], have been discussed. The existence of NDPs surrounded by a hydrated layer indicates that these particles may be suitably used in water [29]. It was reported that denotation NDPs are usually stabilized through termination using functional groups to facilitate further chemical reactions [31]. However, the functional surface groups sometimes enhance agglomeration in the range of several hundred nanometers up to micrometers [32, 33]; excessive aggregation inhibits the lubricating effect of NDPs. The ideal termination group should be one that is closely related to the tribosystem.

In this study, the terminated hydroxyl and carboxyl water-dispersed NDPs (denoted as NDP-OH and $\mathrm{NDP}-\mathrm{COOH}$, respectively) with various additive concentrations are first used as lubricants for the self-mated SiC ball and disk tribopairs. Various experimental conditions combined with different sliding speeds and normal loads were considered. It is deemed disadvantageous to separately discuss the influencing factors of tribology (i.e., sliding speed and normal load) because the combined effect of these factors cannot be emphasized. Hence, the concept of input friction energy, which is defined as the product of speed and normal load, is first investigated in this study.

\section{Experimental}

\subsection{Preparation of NDP-added water}

The detonation NDP dispersion DINNOVARE of the commercial group DAICEL Corporation was used. The surface chemistry of NDPs was characterized by the Fourier transform infrared (FTIR) and transmittance spectra, as shown in Fig. 1. The main peaks in the NDP-COOH are the $\mathrm{OH}$ bond $\left(3,400 \mathrm{~cm}^{-1}\right)$ and $\mathrm{C}=\mathrm{O}$ stretching vibrations (carbonyl groups, 1,770-1,865 $\mathrm{cm}^{-1}$ ) (Fig. 1(a)). In the NDP-OH, the $\mathrm{CH}$ bond $\left(2,800-3,100 \mathrm{~cm}^{-1}\right)$ becomes the main peak; it can be observed that the peaks in the oxygen functional groups $(\mathrm{OH}$ and $\mathrm{C}=\mathrm{O}$ groups) are low (Fig. 1(b)). The particle size distribution is determined by dynamic light scattering measurements using water with a $0.82-\mathrm{cP}$ viscosity at $25{ }^{\circ} \mathrm{C}$, as illustrated in Fig. 2. The average particle diameters of ND- 

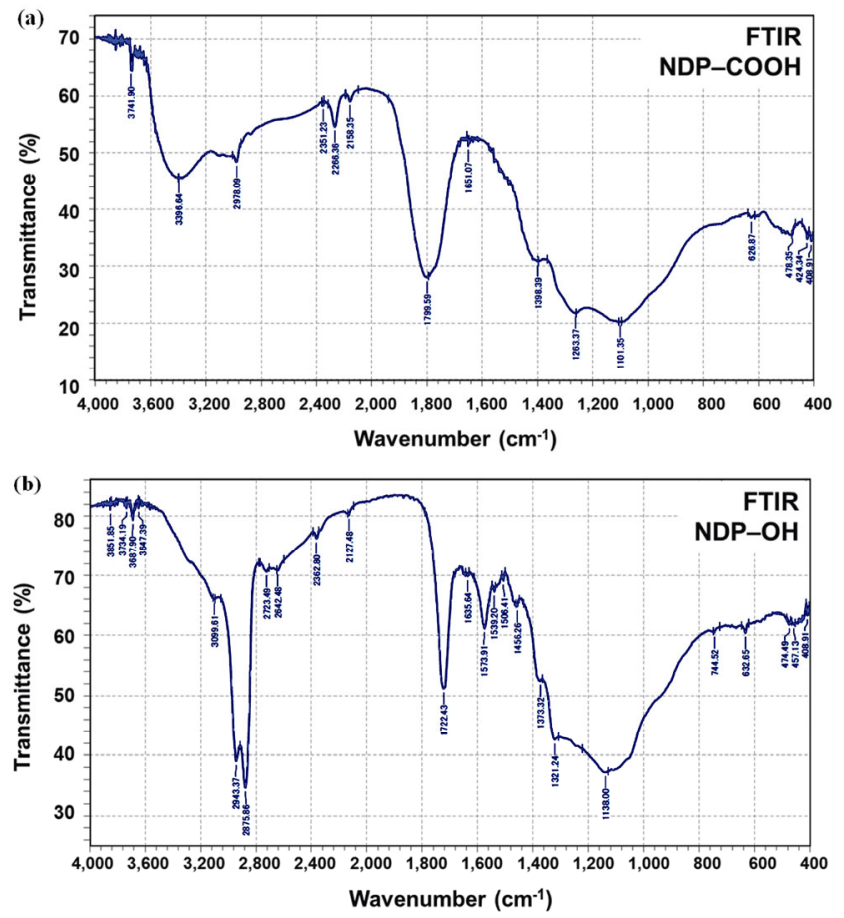

Fig. 1 FTIR transmittance spectra of (a) NDP-COOH and (b) NDP-OH.
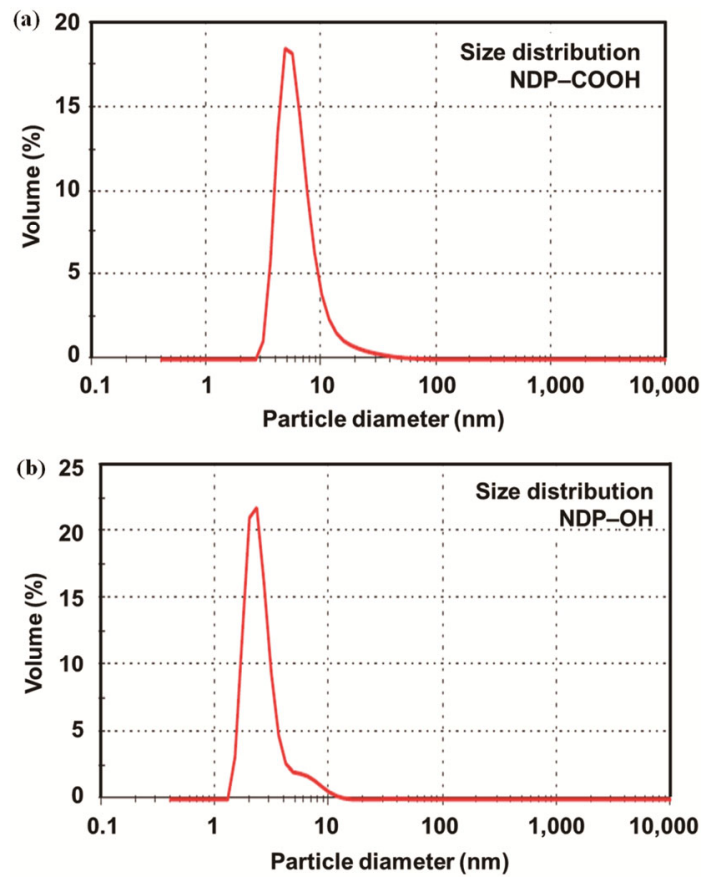

Fig. 2 Size distributions of (a) NDP-COOH and (b) NDP$\mathrm{OH}$.

$\mathrm{COOH}$ and ND-OH are 5.8 and $2.4 \mathrm{~nm}$, respectively. These two NDPs are then dispersed separately in water to form two stock solutions. Arbitrary concentrations $(0,0.001 \mathrm{wt} \%, 0.01 \mathrm{wt} \%, 0.1 \mathrm{wt} \%$, and $1 \mathrm{wt} \%$ ) were prepared by diluting the stock solutions with distilled water. The relevant $\mathrm{pH}$ values and $\zeta$ potentials for each case are summarized in Table 1. To homogenize the lubricant, an ultrasonic bath was firstly used for $12 \mathrm{~min}$, and then for another $5 \mathrm{~min}$ before each test to avoid aggregation.

\subsection{Experimental apparatus and measurements}

The ball-on-disk tribometer is used for all experimental cases. The radii of the $\mathrm{SiC}$ ball and disk are 4 and $15 \mathrm{~mm}$, respectively. The surface profile of the SiC disk specimen is shown in Fig. 3. Its arithmetic mean roughness $(R a)$ is approximately $4.7 \mathrm{~nm}$, which was measured using a surface roughness meter (SURFCOM 1500DX, ACCRETECH). After setting the specimens, a 1-mL aqueous lubricant is spread uniformly on the SiC disk. All tests are performed under ambient conditions (temperature: $25 \pm 3{ }^{\circ} \mathrm{C}$; humidity: $50 \% \pm 3 \%$ ). The sliding speed and applied normal load vary in the ranges of $10-100 \mathrm{~mm} / \mathrm{s}$ and 5-15 N, respectively; the default sliding distance is $100 \mathrm{~m}$ for all tests. Before each test, the specimens were cleaned with acetone and ethanol in an ultrasonic bath for $10 \mathrm{~min}$.

The contact regions of balls and disks were observed using optical microscopes, scanning electron microscope (SEM; SU8020, Hitachi High-technologies Corporation), scanning probe microscope (SPM; E-sweep, Hitachi High-Technologies Corporation), and transmission electron microscope (TEM, Tecnai F20, FEI). Energy

Table $1 \mathrm{pH}$ values and $\zeta$ potentials for two kinds of NDPdispersed water at four concentrations: $1 \mathrm{wt} \%, 0.1 \mathrm{wt} \%, 0.01$ wt $\%$, and $0.001 \mathrm{wt} \%$.

\begin{tabular}{cccccc}
\hline \multirow{2}{*}{$\begin{array}{c}\text { Concentration } \\
(\mathrm{wt} \%)\end{array}$} & \multicolumn{2}{c}{$\mathrm{NDP}-\mathrm{COOH}$} & & \multicolumn{2}{c}{$\mathrm{NDP}-\mathrm{OH}$} \\
\cline { 2 - 3 } \cline { 5 - 6 } & $\mathrm{pH}$ & $\begin{array}{c}\zeta \text { potential } \\
(\mathrm{mV})\end{array}$ & & $\mathrm{pH}$ & $\begin{array}{c}\zeta \text { potential } \\
(\mathrm{mV})\end{array}$ \\
\hline 1 & 9.4 & -40.2 & & 6.2 & +45.7 \\
0.1 & 9.3 & -40.7 & & 6.4 & +45.2 \\
0.01 & 8.6 & -42.8 & & 6.4 & +45.2 \\
0.001 & 8.4 & -43.1 & & 6.7 & +44.4 \\
\hline
\end{tabular}

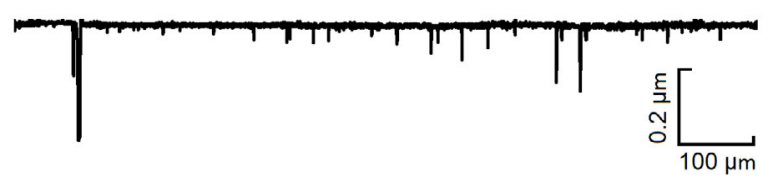

Fig. 3 Surface profile of SiC disk specimen. 
dispersive X-ray spectroscopy (EDX; EMAXEvolution, HORIBA) and X-ray photoelectron spectroscopy (XPS; Quantera SXM, ULVAC-PHI) were utilized to analyze the surface elemental compositions. Moreover, the microscopic contact angle meter (MCA; MCA-3, Kyowa Interface Science) was employed to improve the surface wettability. The specimens were cleaned with pure water in an ultrasonic bath for $4 \mathrm{~min}$ to remove the remaining lubricant and wear particles. Thereafter, they were blow-dried before measurements.

\section{Results and discussion}

\subsection{Effect of water-dispersed NDP}

The typical friction coefficients attained by $\mathrm{SiC} / \mathrm{SiC}$ in water with and without NDPs are shown in Fig. 4. As a result of instability (Fig. 4(a)), it was necessary to smooth the plotted curves to identify the trend of friction (Fig. 4(b)). For this purpose, the moving average method was applied to all data used in
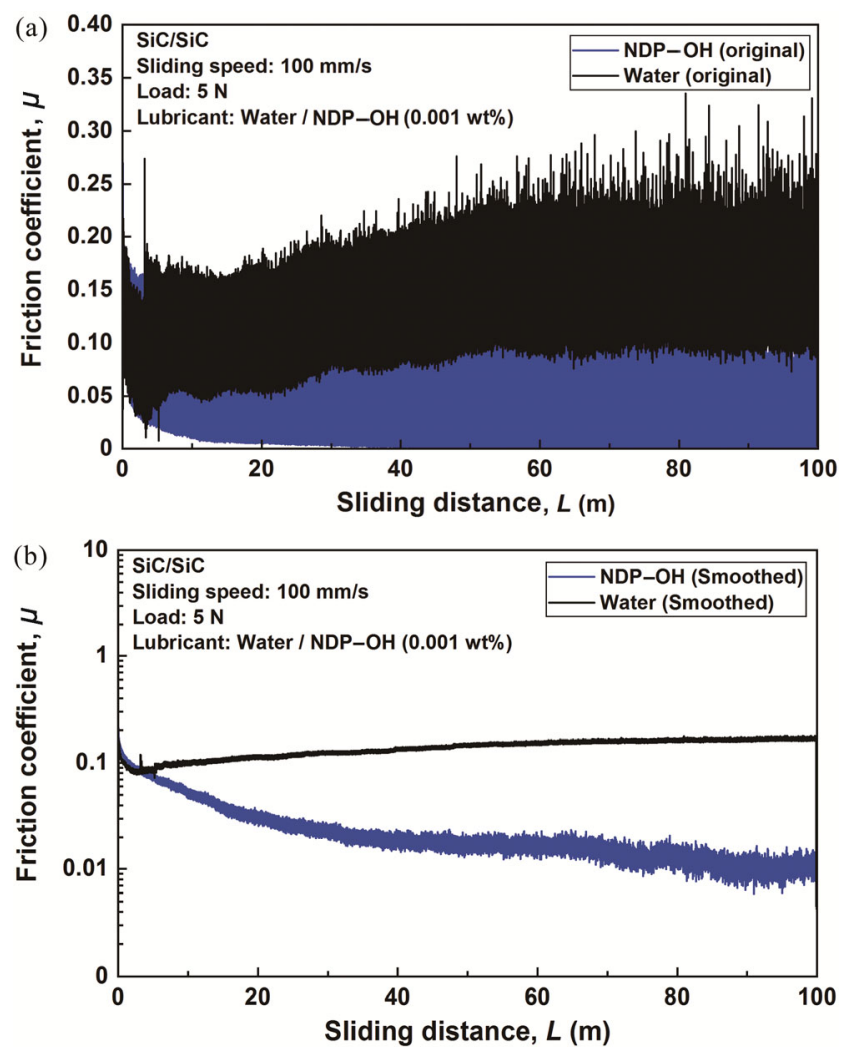

Fig. 4 Friction properties of $\mathrm{SiC} / \mathrm{SiC}$ with sliding in NDP$\mathrm{OH}(0.001 \mathrm{wt} \%)$ and pure water: (a) Original evolution of friction coefficient and (b) smoothed log-scale evolution curve using moving average method. $L$ is the sliding distance, $\mathrm{m}$. this study. It was found that a few meters of sliding were sufficient for the water-dispersed NDPs to complete the running-in and achieve a considerably low friction coefficient (approximately 0.01), demonstrating the superiority of this lubricant over pure water. At the micro-level, this sliding process induces the gradual generation of a thin amorphous layer, i.e., a nanointerface $[15,16]$, on the wear scar, as shown in Fig. 5. This type of layer is mainly formed under the action of tribochemical reactions. The XPS experimental semi-quantitative analysis (Table 2) does not indicate significant differences between the intersurfaces created in pure water and NDP-OH, i.e., the tribochemical reaction in $\mathrm{NDP}-\mathrm{OH}$ is the same as that in water. Hence, it is

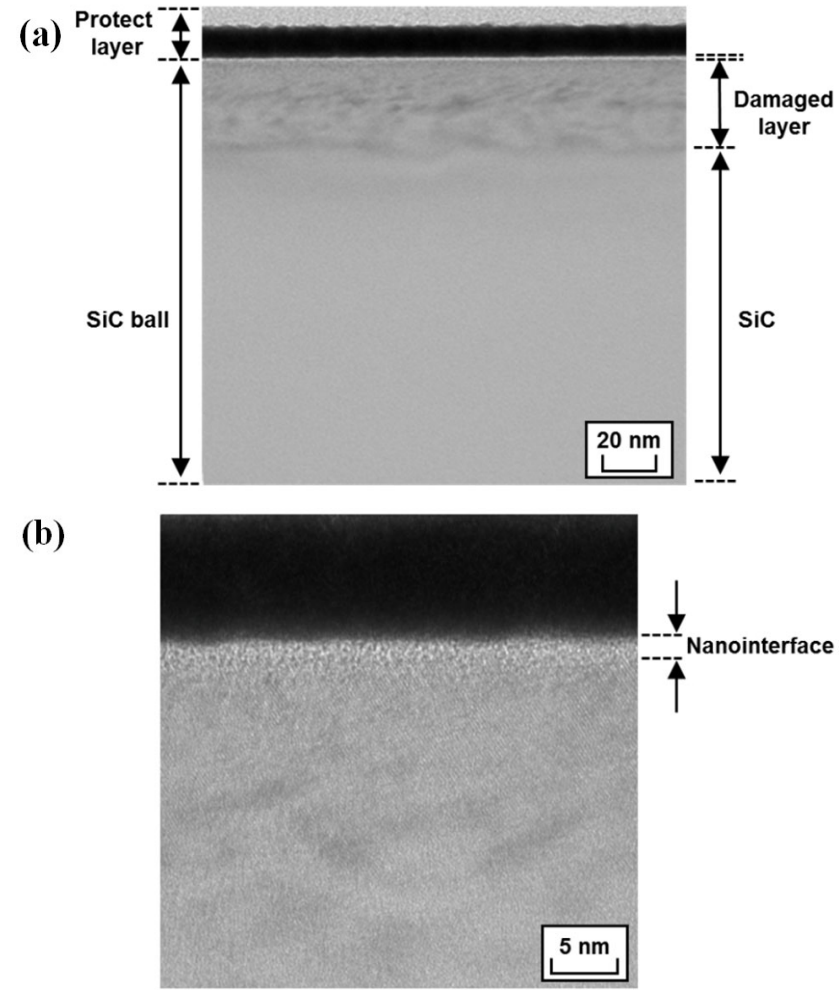

Fig. 5 Cross-sectional TEM images of top wear surface of $\mathrm{SiC}$ ball with (a) global vision and (b) magnified visions around nanointerface observed after $100-\mathrm{m}$ sliding in $0.001 \mathrm{wt} \%$ $\mathrm{NDP}-\mathrm{OH}$.

Table 2 XPS elemental composition analysis of wear scars. The analyzed region possesses a radius of $150 \mu \mathrm{m}$ and a depth of $10 \mathrm{~nm}$.

\begin{tabular}{cccc}
\hline Composition & $\mathrm{C}($ at $\%)$ & $\mathrm{O}($ at $\%)$ & $\mathrm{Si}(\mathrm{at} \%)$ \\
\hline Water & 51.3 & 16.8 & 31.9 \\
NDP-OH & 50.6 & 15.9 & 33.6 \\
\hline
\end{tabular}


assumed that the NDPs act as "catalyst" in water and can induce a faster self-formation of low-friction films on the $\mathrm{SiC}$ wear surface.

To clarify the stability of low-friction behaviors, a long-distance rubbing test was performed. In Fig. 6(a), the low friction afforded by the NDPs is maintained for a minimum distance of 2,000 m. Under the same driving condition, pure water induces the self-mated $\mathrm{SiC}$ to achieve low friction over a rubbing distance of less than $2,000 \mathrm{~m}$. However, it requires more than $1,000 \mathrm{~m}$ to reach the frictional level achieved by water-dispersed NDPs. Furthermore, after every $100 \mathrm{~m}$ of sliding, the rubbing tests were temporarily halted to measure the following in the SiC ball: (1) The wear scar radius is used to estimate the wear amount $(V)$ by assuming that the worn part is an ideal spherical cap, and (2) the contact angle $(\theta)$ of water on the wear surface is used to evaluate the wettability;
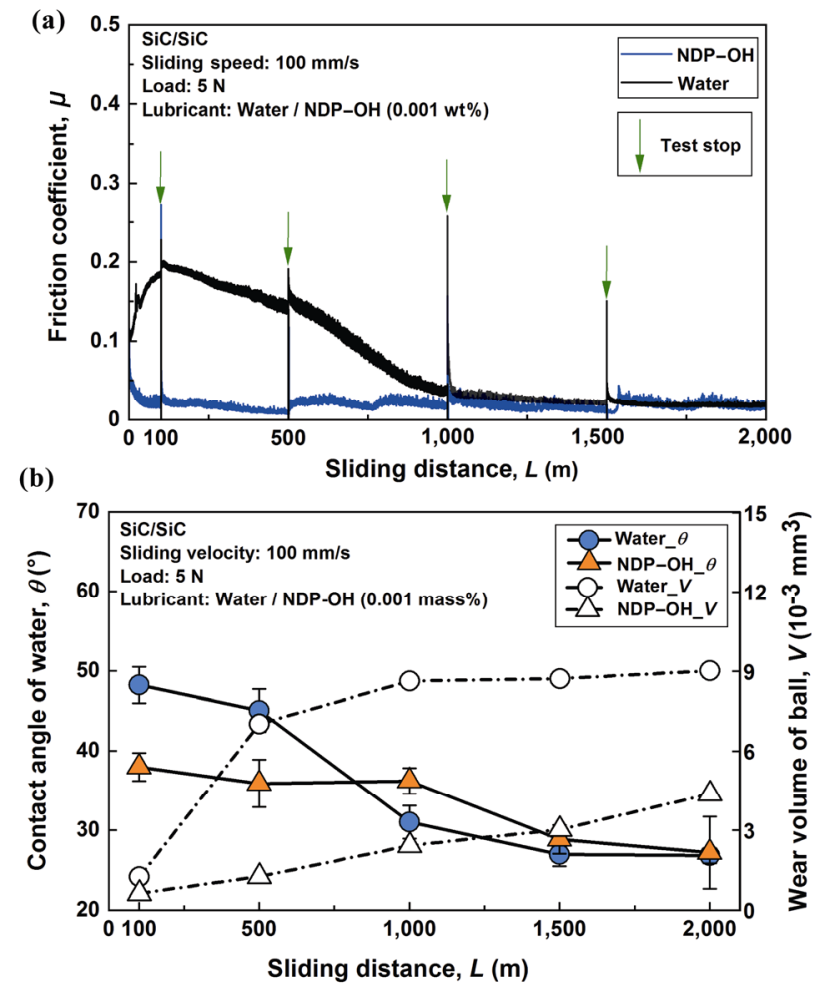

Fig. 6 Tribological performances of 2,000 m-sliding in NDP$\mathrm{OH}(0.001 \mathrm{wt} \%)$ and pure water. Sliding speed and applied normal load are $100 \mathrm{~mm} / \mathrm{s}$ and $5 \mathrm{~N}$, respectively. Tests temporarily stopped at 100,500,1,000, 1,500, and 2,000 m, and properties are measured: (a) Friction evolution; (b) change in contact angle of water on wear surface of $\mathrm{SiC}$ ball (solid line) and tendency of wear amount in ball (dashed line). the results are shown in Fig. 6(b). The measurement shows that $V$ increases practically linearly with sliding in NDP-OH, indicating that the transition in the wear mode does not occur after the first $100 \mathrm{~m}$. As for pure water, although the wear is severe during the running-in period (first 1,000 m), the increase in $V$ is inconsiderable after $1,000 \mathrm{~m}$. The $\theta$ in NDP-OH is always less than $40^{\circ}$ and slightly and steadily decreases with sliding; in water, $\theta$ exhibits a satisfactory decrease over the $500-1,000 \mathrm{~m}$ distance. Interestingly, after 1,000 $\mathrm{m}$, the pure water lubrication system even performs slightly better in all three aspects: friction stability, wear growth rate (practically constant), and wettability. Thus, it is concluded that the NDPs aid in the self-formation of a hydrophilic film in the early stage of sliding, resulting in the low-friction property; thereafter, the expected effects afforded by NDPs are no longer distinct. It is deduced that the utilization of NDP-OH only in the initial sliding may be a reliable design for the $\mathrm{SiC} / \mathrm{SiC}$ water lubrication system.

Nevertheless, although the positive effect of NDPs is compelling, certain critical restrictions should be considered, e.g., termination group and NDP concentration.

\subsection{Effect of termination group and concen- tration of NDPs}

To further clarify the tribological performances with the use of additives, two aspects were considered: (1) Termination types and (2) additive concentrations. The frictional effects of NDP-COOH and NDP$\mathrm{OH}$ at different concentrations compared to pure water are shown in Fig. 7(a). In Fig. 7(a), the average friction coefficient $\left(\mu^{*}\right)$ was calculated using the friction coefficients obtained from the last $10 \%$ sliding distance $(90-100 \mathrm{~m})$. For the NDP-COOH, low friction can be achieved within the concentration range of $0.001-1 \mathrm{wt} \%$, which is wider than that of the NDP-OH. However, once the concentration decreases to $0.001 \mathrm{wt} \%$, the latter yields $\mu^{*}=0.01$ (the minimum average friction coefficient). This sensitivity to the additive concentration can be also observed from the influence of concentration on the specific wear rate $\left(W_{s}\right)$ of the ball, as shown 

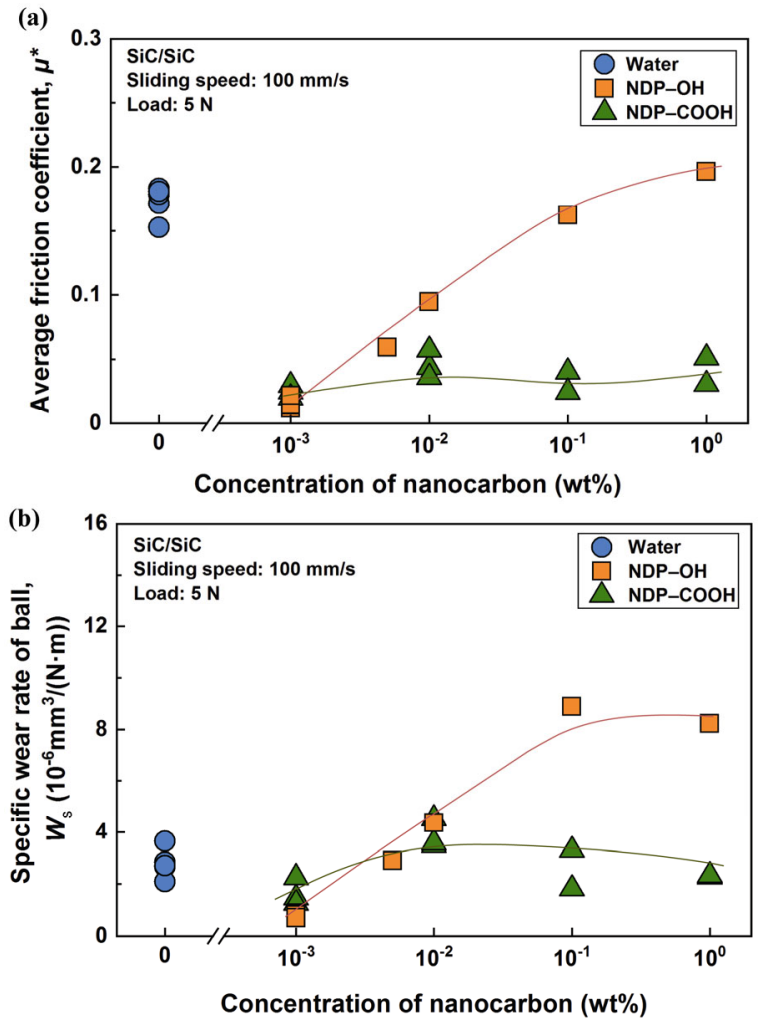

Fig. 7 Effect of concentration and terminations of NDPs on (a) average friction coefficient and (b) specific wear rate of the ball.

in Fig. 7(b). The following equation defines $W_{\mathrm{s}}$ as follows:

$$
W_{\mathrm{s}}=\frac{V}{W \cdot L}
$$

where $W(\mathrm{~N})$ is the applied normal load. Moreover, it is found that both ND-COOH and ND-OH yield lower $W_{\mathrm{s}}$ values than pure water only at a concentration of $0.001 \mathrm{wt} \%$. In particular, a significant disparity between these two NDP dispersions is marked at a high concentration. Under the same driving condition, with a lubricant concentration of $1 \mathrm{wt} \%$, the worn surface of tribopairs was optically observed after the sliding, as shown in Fig. 8. Iridescent films, which cannot be observed on worn surfaces in the NDP-COOH (Figs. 8(a) and 8(b)), partially form on the ball (Fig. 8(c)) and disk (Fig. 8(d)) in NDP-OH. The scar size on the ball in NDP-OH is distinctly bigger than that in the NDP-COOH, corresponding to that shown in Fig. 7(b). Logically, the quantity of iridescent films is consistent with the lubricant concentration, which gradually decreases with the dilution of NDP-
$\mathrm{COOH}$, as shown in Figs. 8(c)-8(h). Until $0.001 \mathrm{wt} \%$, after sliding in the NDP-OH, the contact surfaces are as clear as those in the NDP-COOH.

The typical SEM images of carbon films are shown in Fig. 9(a); the scanned area on the ball is around the edge of the wear scar. The chemical
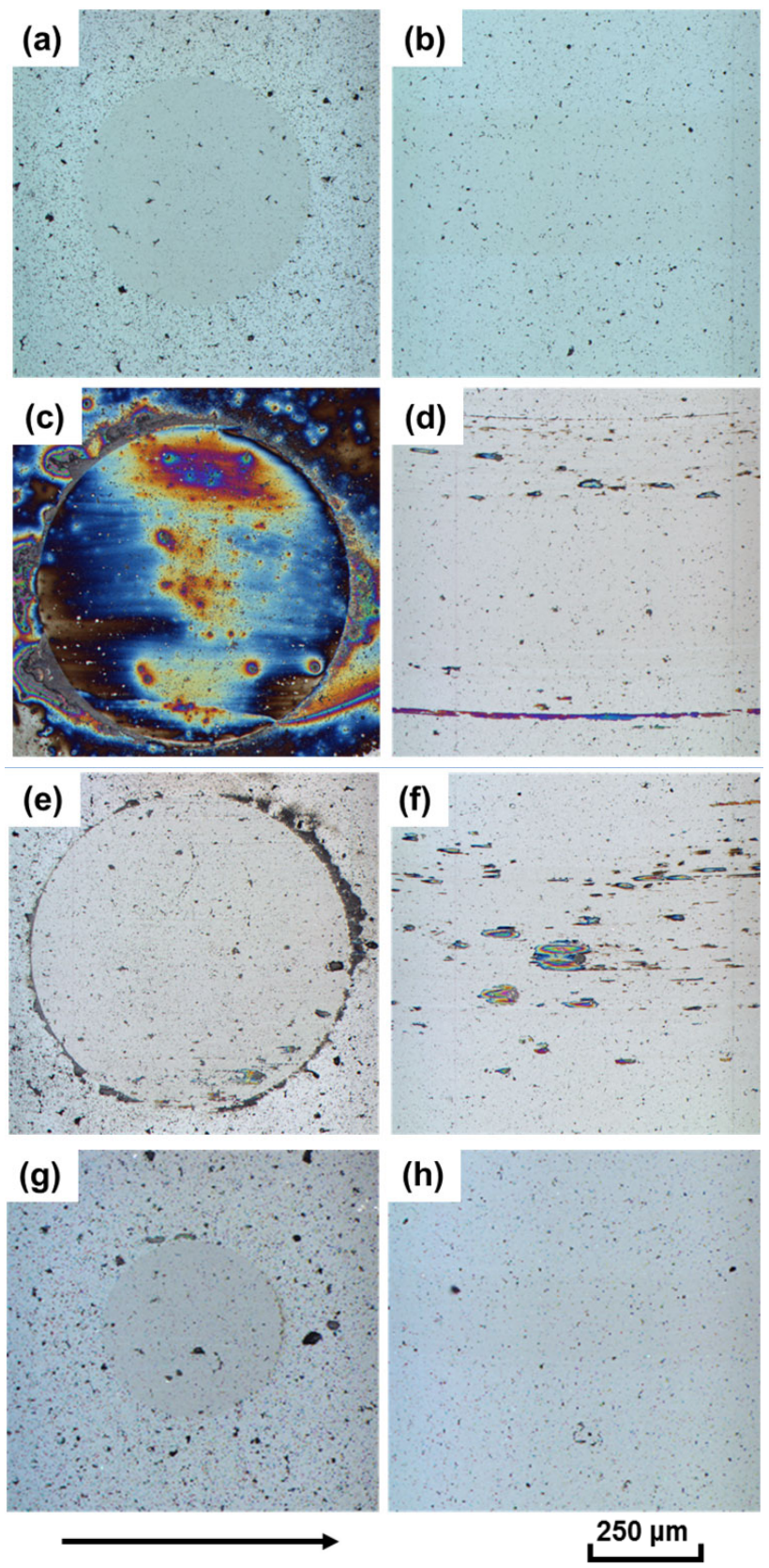

Fig. 8 Optical images of worn surfaces after rubbing-in in water-dispersed NDPs: (a, b) In NDP-COOH (1 wt\%), (c, d) in NDP-OH $(1 \mathrm{wt} \%),(\mathrm{e}, \mathrm{f})$ in NDP-OH $(0.1 \mathrm{wt} \%)$, and $(\mathrm{g}, \mathrm{h})$ in NDP-OH $(0.001 \mathrm{wt} \%)$. Left $(\mathrm{a}, \mathrm{c}, \mathrm{e}, \mathrm{g})$ and right images $(\mathrm{b}$, $\mathrm{d}, \mathrm{f}, \mathrm{h}$ ) are worn surfaces on balls and disks, respectively. Arrows indicate sliding directions of counter material. 
(a)

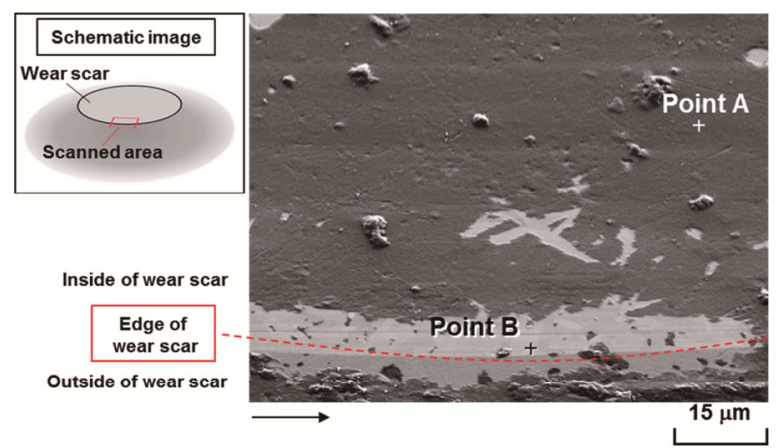

(b)

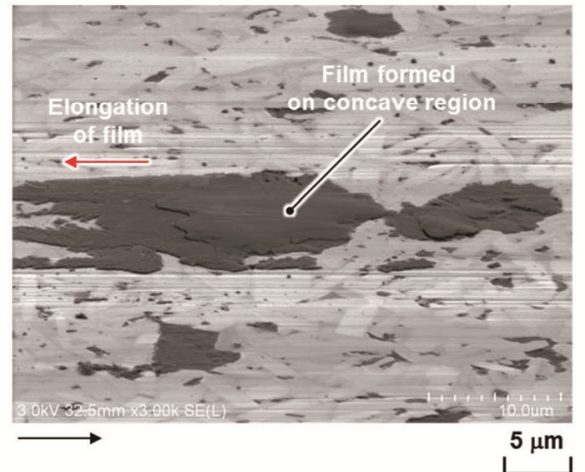

Fig. 9 Typical SEM images of contacting faces. (a) Wear scar in $\mathrm{SiC}$ ball after rubbing-in in ND-OH (1 wt\%); schematic shows the scanned area of specimen, and film (point $\mathrm{A}$ ) and substrate (point B) were analyzed by EDX. (b) Carbon films formed on wear track of SiC disk. Black arrows indicate sliding direction of counter material.

components of films and substrates (points A and B in Fig. 9(a), respectively) were analyzed by EDX, as summarized in Table 3. It is presumed that carbon, which is the dominant element in the films, comes from the $\mathrm{OH}$-terminated lubricant rather than resulting from the tribochemical reaction because the films are formed not only inside but also outside of the wear scar on the ball. The films can be also observed in the surface cavities of the disk that initially exist on the specimen (Fig. 9(b)). Similar to that presented by Sato et al. [34], the carbon films are elongated along the rotation direction of the disk. They also studied the effect of another carbon-based nanoparticle additive: carbon nanohorn

Table 3 Quantitative EDX analysis result of the wear scar of the ball after friction in NDP-OH (1wt\%). Points A and B are shown in Fig. 9(a).

\begin{tabular}{cccc}
\hline Composition & $\mathrm{C}(\mathrm{at} \%)$ & $\mathrm{O}(\mathrm{at} \%)$ & $\mathrm{Si} \mathrm{(at \% )}$ \\
\hline Point A & 98.6 & 1.4 & - \\
Point B & 52.5 & - & 47.5 \\
\hline
\end{tabular}

(CNHs). However, unlike the NDP-OH, the carbon films, which are self-formed from highly concentrated CNHs, act as a solid lubricant, and improve the frictional performance of self-mated $\mathrm{SiC}$ tribopairs. The different lubricating mechanisms are closely related to the construction of additives because CHNs and NDPs are composed of $\mathrm{sp}^{2}$ and $\mathrm{sp}^{3}$ carbon cores, respectively. The occurrence of such types of films is not observed in both cases of high-concentration NDP-COOH (Figs. 8(a) and 8(b)) and low-concentration NDP-OH (Figs. 8(g) and $8(\mathrm{~h}))$, even under SEM. Accordingly, this indicates that the carbon films formed in the NDP$\mathrm{OH}$ are abrasive and have high shear strengths. In contrast, the formation of carbon films is suppressed in the NDP-COOH. A possible explanation is that $\mathrm{SiO}_{2}$, which is one of the products of tribochemical reaction, has a negative $\zeta$ potential in water $(\mathrm{pH} \approx 7)$ [35] and NDP-COOH; they tend to repel each other to inhibit aggregation. In contrast, attraction occurs in the NDP-OH because its $\zeta$ potential is positive, and thus enhancing agglomeration. As a result, the aggregated NDP weakens the lubrication effect by changing the interfacial mechanical reactions, such as shifting from the ball-bearing mode to sliding mode [36, 37]. The Stribeck curves for the extreme concentrations of the two dispersions and pure water are shown in Fig. 10. The highlighted NDP-OH $(0.001 \mathrm{wt} \%)$ curve shifts to the lower bearing characteristic number for practically a full magnitude compared to the pure water curve. That is, a slight addition of NDP-OH improves the loadcarrying capacity of $\mathrm{SiC} / \mathrm{SiC}$ in water by approximately

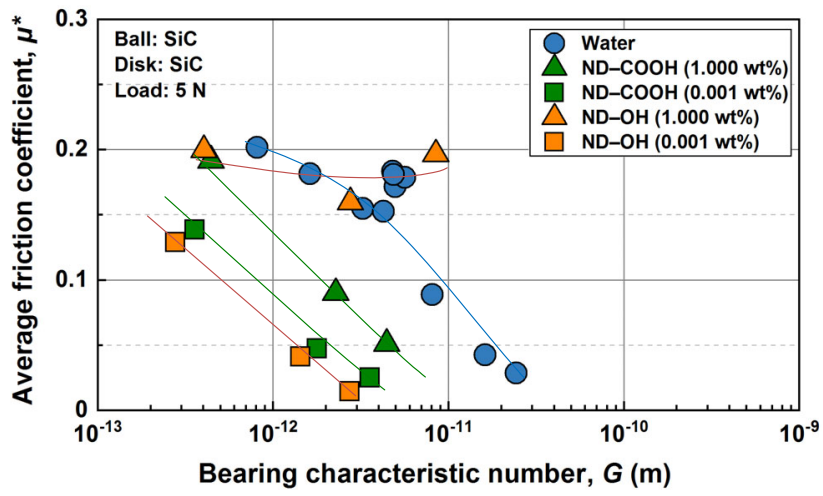

Fig. 10 Stribeck curves in NDP-COOH, NDP-OH, and water. Two concentrations ( $1 \mathrm{wt} \%$ and $0.001 \mathrm{wt} \%$ ) are analyzed for NDP-added lubricants. 
tenfold. Moreover, it is suggested that a moderate aggregation is necessary to improve both wear resistance and frictional performance [37]. This is reflected by the moderate superiority of $0.001-\mathrm{wt} \%$ NDP-OH over 0.001-wt\% NDP-COOH. Moreover, researchers have investigated the effect of hydrogen ions on the lubrication mechanism for ceramic tribopairs $[38,39]$. It was reported that in an acid solution, $\mathrm{H}^{+}$adsorbs on the friction interface because of the protonation reaction, resulting in a positively charged surface. Hence, low friction occurs because of the electrical double layer effect and hydration effect on the positively charged surface. It remains unclear whether the superiority of $0.001-w t \%$ NDP$\mathrm{OH}$ results from its weak acidity. However, in cases of high concentrations, although the lubricants are strongly acidic, the over-aggregated additives dominate the friction mechanisms rather than the $\mathrm{pH}$ value. Further research is necessary to gain more insight into this aspect.

In conclusion, to perform a more reliable tribological application in self-mated $\mathrm{SiC}$ tribopairs, the focus should be on the concentrations and terminations of NDPs. Moreover, frictional properties are closely related to the sliding speed and applied normal loads. Hence, it is necessary to study the influence of such driving conditions in cases where NDPs are added to clearly define the lubricant mechanism.

\subsection{Effect of driving conditions}

To determine the potential influence of friction conditions, nine driving conditions combined with three sliding speeds $(10,50$, and $100 \mathrm{~mm} / \mathrm{s})$ and three normal loads $(5,10$, and $15 \mathrm{~N})$ are presented in this section. The experimental results are first analyzed to summarize the effects of a single factor (i.e., sliding speed or normal load) using the method of controlling variables. It is concluded that the higher the sliding speed, the easier lower friction can be achieved. Similarly, at the same sliding speed, a heavier normal load induces lower friction. It should be noted that unlike the load effect, the influence of speed on water-dispersed NDPs is consistent with that on pure water. According to Chen et al. [40], in the $\mathrm{SiC} / \mathrm{SiC}$ and pure water lubrication systems, the friction coefficient after the running-in process increases with the decrease in sliding speed and the increase in applied normal loads. Accordingly, it is assumed that the increased load promotes the mechanical reactions in terms of the grinding and polishing effects of NDPs, resulting in a smoother nanointerface [40]. This study focuses on the combined effect of the two driving conditions described by the input friction power, $P_{\text {in }}$ (Eq. (3)). It is noteworthy that this value is defined as a scalar quantity and is only used to describe the severity of contact and sliding.

$$
P_{\text {in }}=W \cdot v
$$

According to Fig. 7, it appears that the NDP$\mathrm{COOH}$ concentration does not affect the mechanism of frictional reduction. Hence, the NDP-COOH solutions of different concentrations $(0.1 \mathrm{wt} \%, 0.01$ $w t \%$, and $0.001 \mathrm{wt} \%$ ) were used as lubricants instead of NDP-OH because the latter causes an influencing uncertainty resulting from excessive agglomeration. Pure water (concentration: $0 \mathrm{wt} \%$ ) was used for comparison. The friction coefficient evolution with sliding under the four typical driving conditions is shown in Fig. 11. When $P_{\text {in }}$ is as low as $50 \mathrm{~mW}$ (Fig. 11(a)), pure water and water-dispersed NDPs cannot complete the running-in period in $100 \mathrm{~m}$; hence, low friction cannot be achieved. The outstanding effect of additives compared to pure water lubrication with the increase in $P_{\text {in }}$ is shown in Figs. 11(b) and 11(c). With the increase in $P_{\text {in }}$, the difference in the lubricating ability between water and NDP$\mathrm{COOH}$ becomes less significant. In particular, $\mu$ attains approximately 0.05 even in pure water when $P_{\text {in }}$ is as high as $1,500 \mathrm{~mW}$; this sufficiently approximates that in NDP-COOH (Fig. 11(d)). Typical friction maps on the $360^{\circ}$-calibrated wear track of the SiC disk are shown in Fig. 12. The friction coefficients are scaled by various colors (rainbow bar). As shown in Fig. 12(a), with the NDP-COOH lubrication (0.1 wt\%), less than 30 cycles of sliding (equivalent to several meters) is sufficient to cause most parts of the disk to behave with low friction (indicated in blue). This tendency can be more significantly observed in the friction profiles of two typical numbers of sliding cycles and positions. Under the same driving condition $\left(P_{\text {in }}=500 \mathrm{~mW}\right)$, the distribution of high friction in 

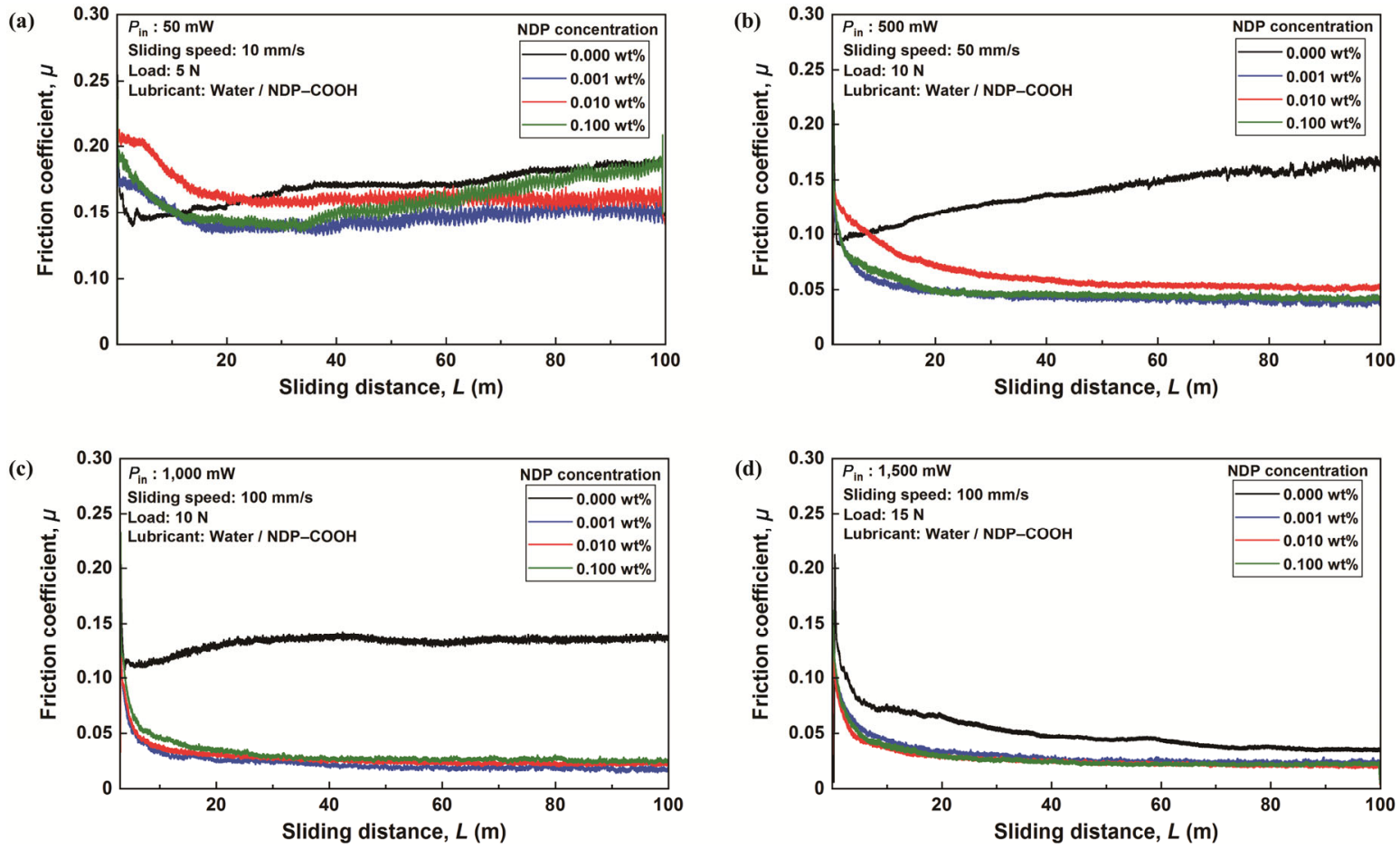

Fig. 11 Friction properties in $100 \mathrm{~m}$-sliding. Four lubricant-dispersed NDPs of different concentrations (0 (pure water), 0.001 $\mathrm{wt} \%, 0.01 \mathrm{wt} \%$, and $0.1 \mathrm{wt} \%)$ under four experimental driving conditions are discussed: (a) $5 \mathrm{~N}$ and $10 \mathrm{~mm} / \mathrm{s}\left(P_{\text {in }}=50 \mathrm{~mW}\right)$; (b) $10 \mathrm{~N}$ and $50 \mathrm{~mm} / \mathrm{s}\left(P_{\text {in }}=500 \mathrm{~mW}\right) ;\left(\right.$ c) $10 \mathrm{~N}$ and $100 \mathrm{~mm} / \mathrm{s}\left(P_{\text {in }}=1,000 \mathrm{~mW}\right) ;\left(\right.$ d) $15 \mathrm{~N}$ and $100 \mathrm{~mm} / \mathrm{s}\left(P_{\text {in }}=1,500 \mathrm{~mW}\right)$.
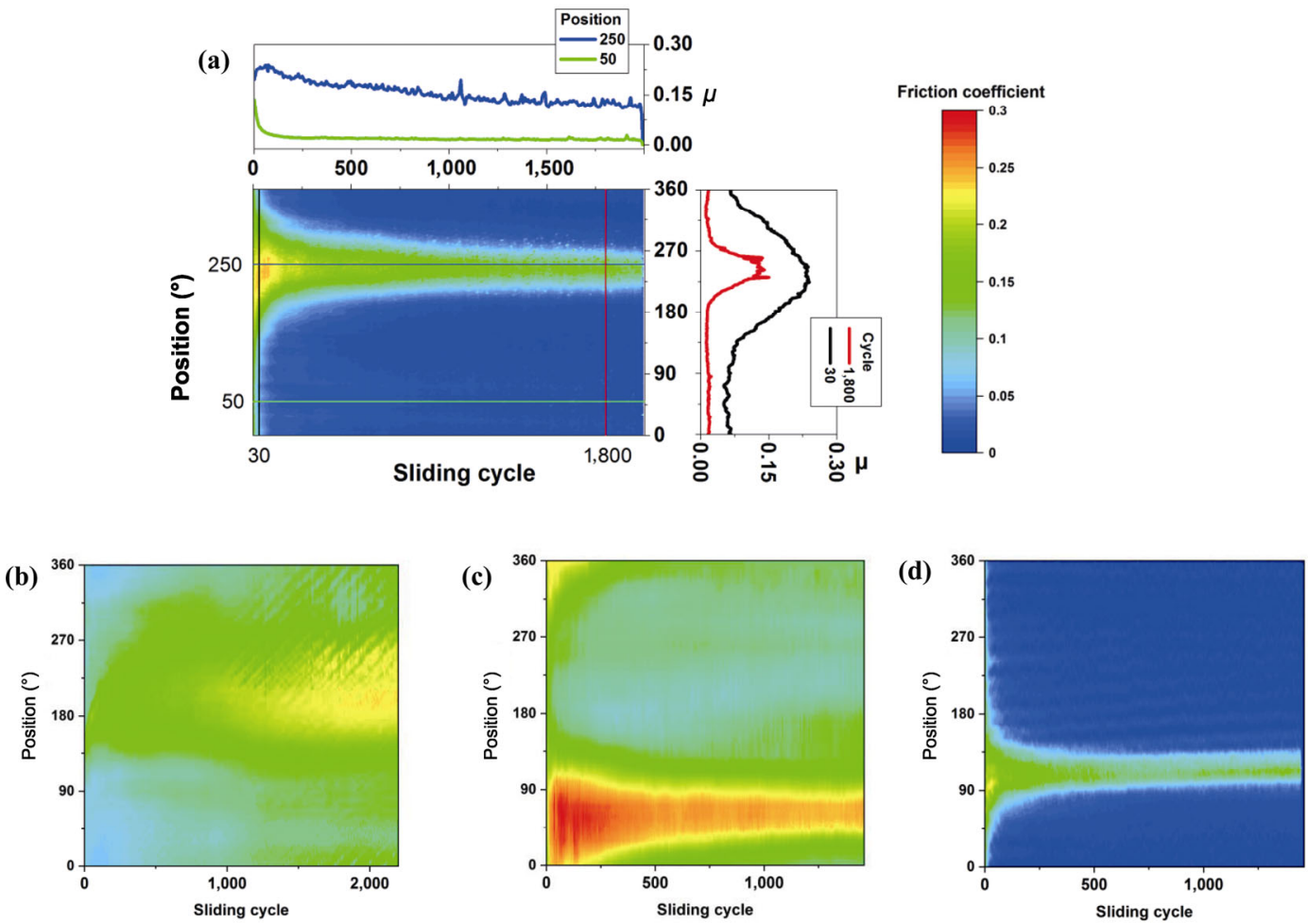

Fig. 12 Friction map of wear track on SiC disk with sliding: (a) In NDP-COOH $(0.1 \mathrm{wt} \%)$ and $P_{\text {in }}=500 \mathrm{~mW}(10 \mathrm{~N}$ and $50 \mathrm{~mm} / \mathrm{s})$; top and right curves represent friction evolutions in two wear positions $\left(247^{\circ}\right.$ and $\left.50^{\circ}\right)$ and two sliding cycles $\left(30^{\text {th }}\right.$ and $\left.1,800^{\text {th }}\right)$, respectively; (b) in water and $P_{\text {in }}=500 \mathrm{~mW}$; (c) in NDP-COOH $(0.1 \mathrm{wt} \%)$ and $P_{\text {in }}=50 \mathrm{~mW}(5 \mathrm{~N}$ and $10 \mathrm{~mm} / \mathrm{s})$; (d) in NDP-COOH $(0.1 \mathrm{wt} \%)$ and $P_{\text {in }}=1,500 \mathrm{~mW}(15 \mathrm{~N}$ and $100 \mathrm{~mm} / \mathrm{s})$. Rainbow scale bar describes intensity of friction coefficients and applies to all four cases. 
pure water (Fig. 12(b)) is considerably more dispersed than that in NDP-COOH. Sliding makes the friction more severe everywhere on the disk; this is consistent with the friction profile shown in Fig. 11(b). This distinct difference, which is caused by changing the lubricant concentration from 0 to $0.001 \mathrm{wt} \%$, qualitatively demonstrates the dissimilarity of lubrication mechanisms. Meanwhile, Figs. 12(c) and 12(d), quantitatively show that a higher $P_{\text {in }}$ results in a better frictional behavior. Notably, in $\mathrm{NDP}-\mathrm{COOH}$, at all applied $P_{\text {in }}$ and concentrations, a high-friction region remains on the disk even though its crest and width decrease (evolution of $250^{\circ}$ position and $1,800^{\text {th }}$ sliding cycle shown in Fig. 12(a), respectively). This only occurs in pure water when $P_{\text {in }}=1,500 \mathrm{~mW}$, which explains why noise appears in the frictional profiles (Fig. 4(a)). To gain more information regarding this phenomenon, further research is necessary. Moreover, a smoother wear surface, which is achieved by low friction, can be observed on the ball and disk. The typical SPM images of the wear scar on the disk (Fig. 13) show that the roughness differences after the rubbing-in at $P_{\text {in }}=50$ and $500 \mathrm{~mW}$ are severe. That is, although NDP-COOH induces the generation of a smoother surface within a shorter sliding distance, the energy provided by the driving conditions should also be considered as an important influencing factor. The frictional behaviors under the same $P_{\text {in }}$ but with different components, i.e.,

(a)
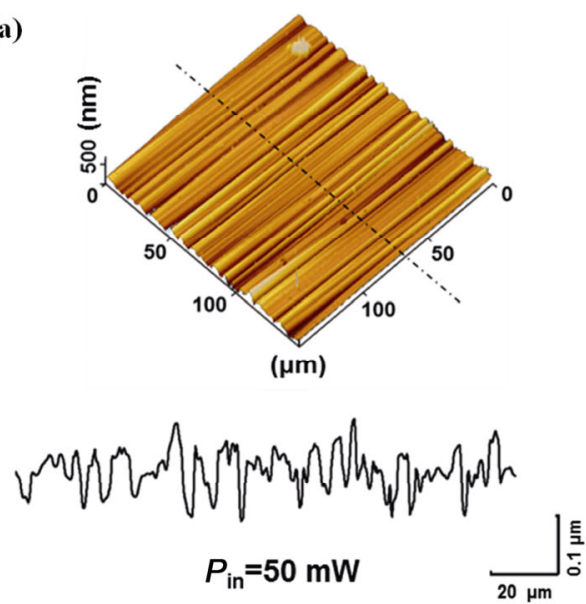

$500 \mathrm{~mW}(5 \mathrm{~N} \times 100 \mathrm{~mm} / \mathrm{s}$ and $10 \mathrm{~N} \times 50 \mathrm{~mm} / \mathrm{s})$, are also compared. In addition to the smoothness of curves, the friction evolutions are considerably similar, as shown in Fig. 14. Focusing on the value of $\mu$ after sliding every $100 \mathrm{~m}$, the difference between the two sliding conditions is considerably small in both pure water and water-dispersed NDPs. The relevant $\mu$ values in NDP-COOH for calculating the average value in the cases with three concentrations are 0.036 and 0.039 for $5 \mathrm{~N} \times$ $100 \mathrm{~mm} / \mathrm{s}$ and $10 \mathrm{~N} \times 50 \mathrm{~mm} / \mathrm{s}$, respectively. It is found that the former condition $(5 \mathrm{~N} \times 100 \mathrm{~mm} / \mathrm{s})$ with a sliding speed twice faster than the latter yields a smaller friction coefficient although the applied normal load is lower (one half that of the latter). Further studies are necessary to clarify the possible quantitative balance between the influences of the two components.

The global $\mu^{*}$ distribution in various $P_{\text {in }}$ values and concentrations are shown in Fig. 15(a). The performances of water and NDP-COOH (round and square, respectively) are separated by a supposed curve (black line) obtained from the data of NDP-COOH $(0.001 \mathrm{wt} \%)$ via the power-function fitting method. Under this curve, three typical $P_{\text {in }}$ regions, Zone I (50 $\left.\mathrm{mW}<P_{\text {in }}<200 \mathrm{~mW}\right)$, Zone II $\left(200 \mathrm{~mW}<P_{\text {in }}<1,500 \mathrm{~mW}\right)$, and Zone III $\left(P_{\text {in }}>\right.$ $1,500 \mathrm{~mW}$ ) were proposed to classify the frictional properties. Generally, compared with pure water, $\mathrm{NDP}-\mathrm{COOH}$ exhibits better performances in all the

(b)
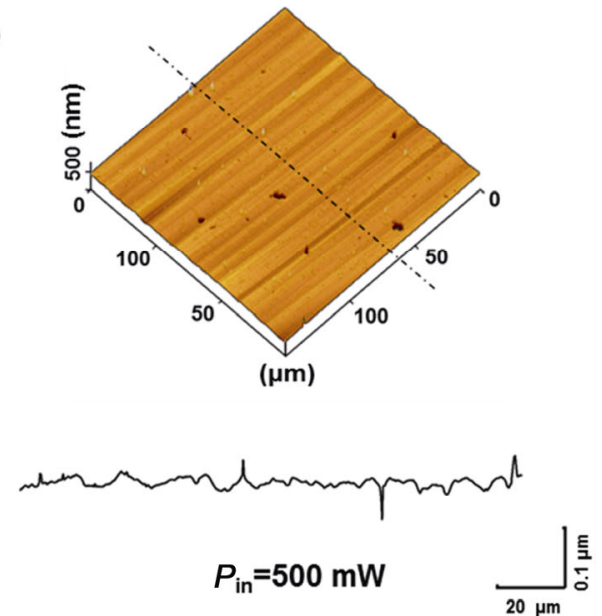

Fig. 13 Typical SPM images of randomly sampled wear profiles on SiC disk after $100 \mathrm{~m}$-sliding in NDP-COOH (0.1 wt\%) with $P_{\text {in }}=$ (a) $50 \mathrm{~mW}$ and (b) $500 \mathrm{~mW}$. Arithmetic average roughness of (a, b) are 30.79 and 7.97 nm, respectively. Surface profile of section marked by dashed line is shown at bottom of each image. 


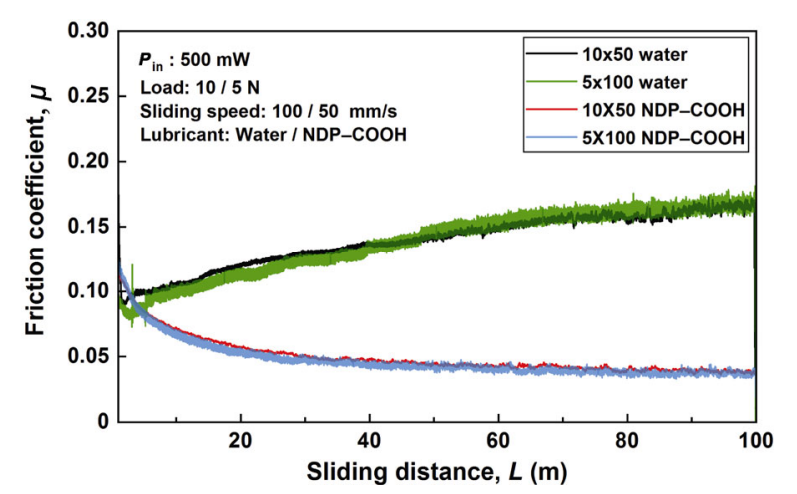

Fig. 14 Friction evolutions in water and NDP-COOH at $P_{\text {in }}=500 \mathrm{~mW}$ combined at $10 \mathrm{~N} \times 50 \mathrm{~mm} / \mathrm{s}$ and $5 \mathrm{~N} \times$ $100 \mathrm{~mm} / \mathrm{s}$. Friction coefficients in NDP-COOH are plotted as average curves fitted from those at three concentrations $(0.1 \mathrm{wt} \%, 0.01 \mathrm{wt} \%$, and $0.001 \mathrm{wt} \%)$.
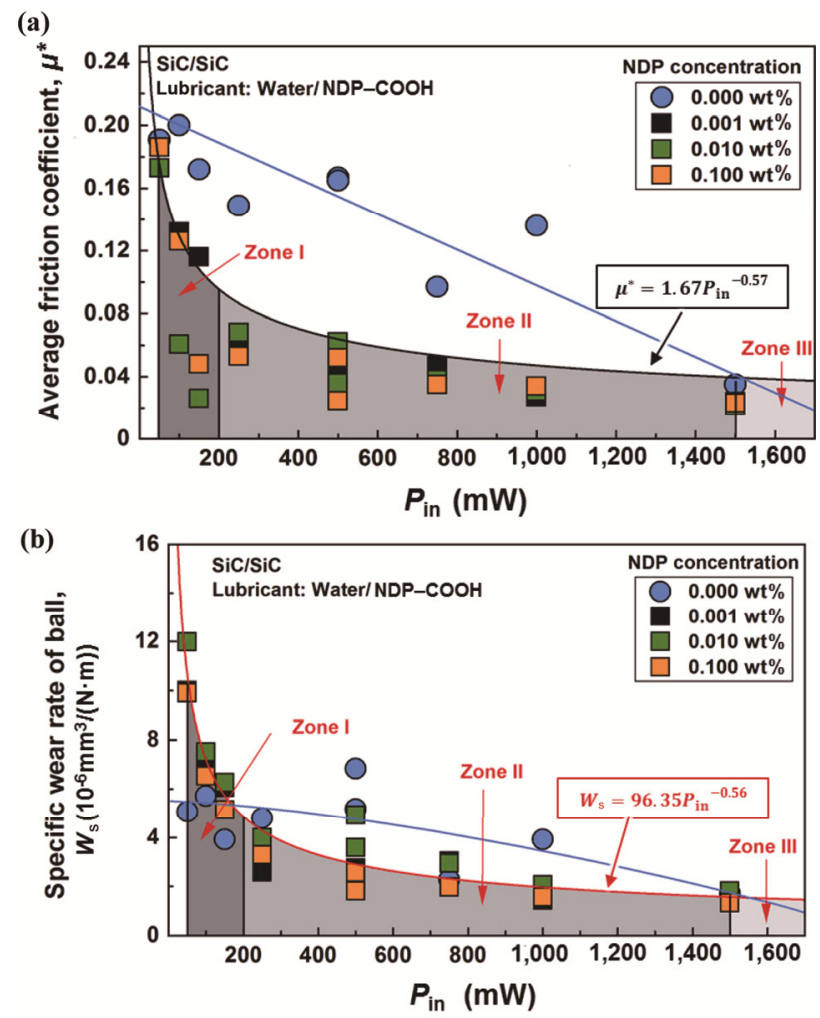

Fig. 15 Sliding properties at $P_{\text {in }}$ values by lubricating with NDP-COOH of various concentrations (0-0.1 wt\%). Driving conditions are divided into three zones (Zone I: $50 \mathrm{~mW}$ $<P_{\text {in }}<200 \mathrm{~mW}$; Zone II: $200 \mathrm{~mW}<P_{\text {in }}<1,500 \mathrm{~mW}$; Zone III: $P_{\text {in }}>1,500 \mathrm{~mW}$ ) and distinguished by three gray areas. (a) Evolution of average friction coefficients. Power curve is fitted from data of $0.001 \mathrm{wt} \%$ with a high coefficient of determination $\left(R^{2}\right)$ of 0.957 . (b) Profiles of specific wear rates of $\mathrm{SiC}$ ball. Red curve indicates decreasing tendency and fitted from NDP-COOH data in $0.001 \mathrm{wt} \%, 0.01 \mathrm{wt} \%$, and $0.1 \mathrm{wt} \%$ with $R^{2}=0.93$. Blue curves indicate performance tendency in the water. driving cases although its influence weakens as $P_{\text {in }}$ increases. The tendency of frictional behaviors in pure water (blue line) intersects with the supposed curve in Zones I and III; accordingly, it can be predicted that it is unnecessary to add NDP-COOH when $P_{\text {in }}$ is considerably low and high, respectively. However, the excellent performance of NDP-COOH is observed in Zone I. In this zone, the difference caused by the concentrations is remarkably significant; the specific wear rate of the ball is shown in Fig. 15(b). It can be observed that the distribution of all NDP-added cases converges well such that the tendency of the curve (the red line) can be fitted with a $R^{2}$ value that is as high as 0.92 . In the majority of cases, low friction occurs with low $W_{\mathrm{s}}$, however, in Zone I, the $W_{s}$ value in NDP-COOH is higher than that in pure water.

In conclusion, it is assumed that the input driving conditions affect the running-in process by influencing the balance between the tribochemical and mechanical reactions: The mechanical reaction dominates Zone I. The NDPs exhibit their distinct property of abrasive polishing, which causes the coincidence of low friction and high amount of wear, which are sensitive to variations in concentration because concentration is closely related to the polishing ability. Interestingly, the median concentration $(0.01 \mathrm{wt} \%)$ yields the lowest friction despite causing the highest wear in the low $P_{\text {in }}$ region. In Zone II, the mechanical reaction is less significant, and the driving condition is conducive to the generation of a tribochemically dominated nanointerface. The NDPs thus exhibit their direct lubrication ability, as follows: Functioning as a nano-bearing to transform sliding friction into rolling friction [26]; embedding into the substrate cavities to improve the surface hardness [27, 28]; carrying water into asperities to form hydrodynamic films [26, 29]. Up to Zone III, the driving power is sufficiently high to cause the appearance of a smooth interface in less than $100 \mathrm{~m}$ even without the presence of NDPs. Hence, the lubrication gain afforded by the NDPs becomes limited.

The $W_{\mathrm{s}}$ values in NDP-COOH, which are represented by squares in Fig. 15(b), are scattered along a quasi-inverse proportion curve. Accordingly, after 
data transformation, a proportional relationship between $W_{\mathrm{s}}$ and $1 / \sqrt{P_{\text {in }}}$ is proposed, as shown in Fig. 16. This equation, $W_{\mathrm{s}}=70.37 / \sqrt{P_{\text {in }}}$, can be used as a reference for the application of NDP-COOH in the self-mated $\mathrm{SiC}$ tribosystem.

\section{Conclusions}

1) In the proposed water-dispersed NDPs, a few meters of sliding is sufficient to cause the selfmated $\mathrm{SiC}$ tribopairs to adequately perform with low friction. A smooth and hydrophilic interface, which is essential for low friction, appears considerably faster in the water-dispersed NDPs than in pure water. The effect of NDPs is finite; hence, the use of a small amount of nanodiamonds only in the initial running-in for the $\mathrm{SiC} / \mathrm{SiC}$ water lubrication tribosystem is suggested.

2) Under the driving condition in which the load and speed are $5 \mathrm{~N}$ and $100 \mathrm{~mm} / \mathrm{s}$, respectively, the slight addition of hydroxyl-terminated NDPs (0.001 $\mathrm{wt} \%$ ) in the self-mated $\mathrm{SiC}$ water-lubrication tribosystem aids in significantly decreasing the friction and specific wear rate. Moreover, the load-carrying capacity approximately increases tenfold than when pure water is employed. However, excessively high concentrations induce the generation of carbon films, resulting in a high and unstable frictional performance. In contrast, carboxyl-terminated NDPs yield a low friction coefficient (less than 0.05) over a wide concentration range $(0.001 \mathrm{wt} \%-1 \mathrm{wt} \%)$ because the film formation by the NDP aggregation

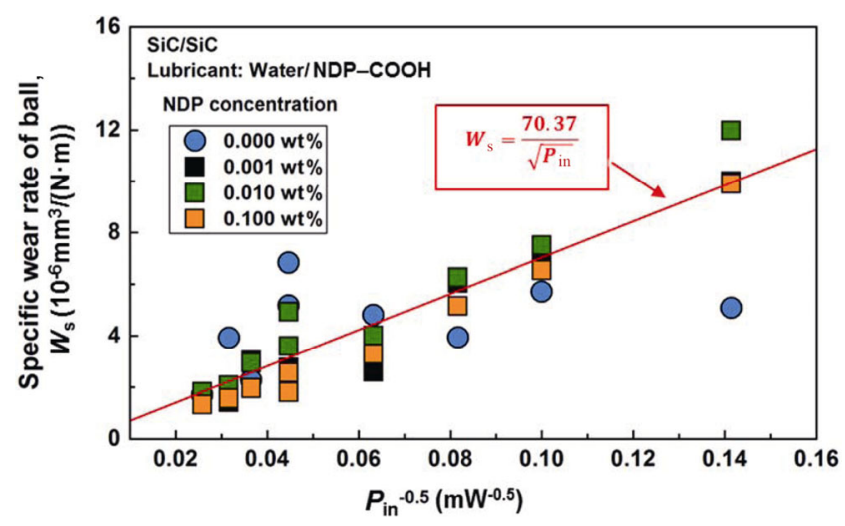

Fig. 16 Relationship between the specific wear rate of ball and $P_{\text {in }}^{-0.5}$. Red curve fitted from NDP-COOH data in 0.001 wt $\%, 0.01$ wt $\%$, and 0.1 wt $\%$ with $R^{2}=0.97$. is inhibited by the opposite $\zeta$ potential of additives and wear particles.

3) In the two types of COOH-terminated NDPs or pure water, the higher the input driving power, the faster the generation of the low-friction interface. Various quantities of input driving power allow the NDPs to implement diverse lubrication mechanisms. At a low $P_{\text {in }}(<200 \mathrm{~mW})$, low friction appears with a high wear rate. At a median $P_{\text {in }}(200 \mathrm{~mW}<$ $P_{\text {in }}<1,500 \mathrm{~mW}$ ), low friction and low wear rate are simultaneously observed. Moreover, the excellent lubrication ability of additives becomes less significant. When $P_{\text {in }}$ is as high as $1,500 \mathrm{~mW}$, pure water is sufficient to allow the $\mathrm{SiC} / \mathrm{SiC}$ tribopair to achieve low friction over a short sliding distance (100 m).

4) Under the NDP-COOH lubrication, the specific wear amount of the $\mathrm{SiC}$ ball obeys a proportional relationship with $1 / \sqrt{P_{\text {in }}}$ as $W_{\mathrm{s}}=70.37 / \sqrt{P_{\text {in }}}$.

\section{Acknowledgements}

The authors would like to express sincerely thanks to the Daicel Corporation for providing nanodiamond, and Mr. Norihiro Kimoto from Daicel Corporation for his valuable discussion.

\section{References}

[1] Fischer T E, Tomizawa H. Interaction of tribochemistry and microfracture in the friction and wear of silicon nitride. Wear 105(1): 29-45 (1985)

[2] Tomizawa H, Fischer T E. Friction and wear of silicon nitride and silicon carbide in water: Hydrodynamic lubrication at low sliding speed obtained by tribochemical wear. ASLE Trans 30(1): 41-46 (1987)

[3] Sasaki S. The effects of the surrounding atmosphere on the friction and wear of alumina, zirconia, silicon carbide and silicon nitride. Wear 134(1): 185-200 (1989)

[4] Gates R S, Hsu S M, Klaus E E. Tribochemical mechanism of alumina with water. Tribol Trans 32(3): 357-363 (1989)

[5] Andersson P. Water-lubricated pin-on-disc tests with ceramics. Wear 154(1): 37-47 (1992)

[6] Erickson L C, Blomberg A, Hogmark S, Bratthäll J. Tribological characterization of alumina and silicon 
carbide under lubricated sliding. Tribol Int 26(2): 83-92 (1993)

[7] Chen M, Kato K, Adachi K. The difference in running-in period and friction coefficient between self-mated $\mathrm{Si}_{3} \mathrm{~N}_{4}$ and $\mathrm{SiC}$ under water lubrication. Tribol Lett 11(1): 23-28 (2001)

[8] Chen M, Kato K, Adachi K. Friction and wear of self-mated $\mathrm{SiC}$ and $\mathrm{Si}_{3} \mathrm{~N}_{4}$ sliding in water. Wear 250(1-12): 246-255 (2001)

[9] Yoshimura M, Kase J I, Sōmiya S. Oxidation of SiC powder by high-temperature, high-pressure $\mathrm{H}_{2} \mathrm{O} . J$ Mater Res 1(1): 100-103 (1986)

[10] Gogotsi Y G, Yoshimura M. Formation of carbon films on carbides under hydrothermal conditions. Nature 367(6464): 628-630 (1994)

[11] Gogotsi Y, Yoshimura M. Degradation of SiC (Tyranno) fibres in high-temperature, high-pressure water. J Mater Sci Lett 14(10): 755-759 (1995)

[12] Presser V, Heon M, Gogotsi Y. Carbide-derived carbonsfrom porous networks to nanotubes and graphene. $A d v$ Funct Mater 21(5): 810-833 (2011)

[13] Gogotsi Y, Presser V. Carbon Nanomaterials. 2nd edn. Boca Raton (USA): CRC Press, 2014: 396-399.

[14] Lin Y C, Kao C H. A study on surface polishing of SiC with a tribochemical reaction mechanism. Int $J A d v$ Manuf Technol 25(1-2): 33-40 (2005)

[15] Adachi K. Nanointerface for superior tribological properties of silicon carbide in water. In Proceedings of the 5th World Tribology Congress, Torino, Italy, 2013: 1096.

[16] Nishikawa Y, Noguchi K, Takeno T, Adachi K. Surface texture to improve friction properties by forming smoother surface on silicon-based ceramics in water. In Proceedings of the 5th World Tribology Congress, Torino, Italy, 2013: 995.

[17] Wang X L, Kato K, Adachi K, Aizawa K. The effect of laser texturing of $\mathrm{SiC}$ surface on the critical load for the transition of water lubrication mode from hydrodynamic to mixed. Tribol Int 34(10): 703-711 (2001)

[18] Wang X L, Kato K, Adachi K, Aizawa K. Loads carrying capacity map for the surface texture design of $\mathrm{SiC}$ thrust bearing sliding in water. Tribol Int 36(3): 189-197 (2003)

[19] Adachi K, Kato K, Otsuka K, Wang X. Fundamental of water lubrication-Effects of surface texturing on load carrying capacity between $\mathrm{SiC}$ surfaces sliding in water. In Proceedings of International Tribology Conference, KOBE, 2005: 47.

[20] Wang X L, Adachi K, Otsuka K, Kato K. Optimization of the surface texture for silicon carbide sliding in water.
Appl Surf Sci 253(3): 1282-1286 (2006)

[21] Berman D, Erdemir A, Sumant A V. Graphene: A new emerging lubricant. Mater Today 17(1): 31-42 (2014)

[22] Liu Y F, Ge X Y, Li J J. Graphene lubrication. Appl Mater Today 20: 100662 (2020)

[23] Ge X Y, Li J J, Luo R, Zhang C H, Luo J B. Macroscale superlubricity enabled by the synergy effect of grapheneoxide nanoflakes and ethanediol. ACS Appl Mater Interfaces 10(47): 40863-40870 (2018)

[24] Ge X Y, Li J J, Wang H D, Zhang C H, Liu Y H, Luo J B. Macroscale superlubricity under extreme pressure enabled by the combination of graphene-oxide nanosheets with ionic liquid. Carbon 151: 76-83 (2019)

[25] Wu P, Chen X C, Zhang C H, Luo J B. Synergistic tribological behaviors of graphene oxide and nanodiamond as lubricating additives in water. Tribol Int 132: 177-184 (2019)

[26] Chen Z, Liu Y H, Luo J B. Superlubricity of nanodiamonds glycerol colloidal solution between steel surfaces. Colloids Surf A: Physicochem Eng Aspects 489 400-406 (2016)

[27] Chou C C, Lee S H. Tribological behavior of nanodiamond-dispersed lubricants on carbon steels and aluminum alloy. Wear 269(11-12): 757-762 (2010)

[28] Alias A A, Kinoshita H, Fujii M. Tribological properties of diamond nanoparticle additive in water under a lubrication between steel plate and tungsten carbide ball. J Adv Mech Des, Syst, Manuf 9(1): 14-00401 (2015)

[29] Korobov M V, Avramenko N V, Bogachev A G, Rozhkova N N, Ōsawa E. Nanophase of water in Nanodiamond gel. J Phys Chem C 111(20): 7330-7334 (2007)

[30] Shenderova O, Vargas A, Turner S, Ivanov D M, Ivanov M G. Nanodiamond-based nanolubricants: Investigation of friction surfaces. Tribol Trans 57(6): 1051-1057 (2014)

[31] Mochalin V N, Shenderova O, Ho D, Gogotsi Y. The properties and applications of nanodiamonds. Nat Nanotechnol 7(1): 11-23 (2012)

[32] Xu X Y, Yu Z M, Zhu Y W, Wang B C. Influence of surface modification adopting thermal treatments on dispersion of detonation nanodiamond. J Solid State Chem 178(3): 688-693 (2005)

[33] Krüger A, Liang Y J, Jarre G, Stegk J. Surface functionalisation of detonation diamond suitable for biological applications. J Mater Chem 16(24): 2322 2328 (2006)

[34] Sato H, Takeno T, Adachi K. Formation of lubricious carbon films by added carbon nanohorns in water. Tribol 
Online 11(2): 455-459 (2016)

[35] Sun D, Kang S F, Liu C L, Lu Q J, Cui L F, Hu B. Effect of zeta potential and particle size on the stability of $\mathrm{SiO}_{2}$ nanospheres as carrier for ultrasound imaging contrast agents. Int J Electrochem Sci 11(10): 8520-8529 (2016)

[36] Yu H L, Xu Y, Shi P J, Xu B S, Wang X L, Liu Q. Tribological properties and lubricating mechanisms of $\mathrm{Cu}$ nanoparticles in lubricant. Trans Nonferr Met Soc China 18(3): 636-641 (2008)

[37] Guo D, Xie G X, Luo J B. Mechanical properties of nanoparticles: Basics and applications. J Phys D: Appl

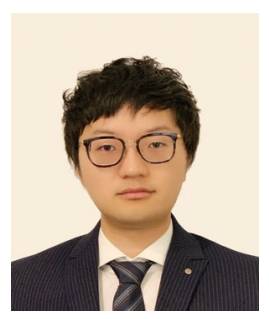

Xudong WANG. He got his M.S. and Ph.D. degrees in physic and engineering from University of Paris-Saclay, France, in 2016 and

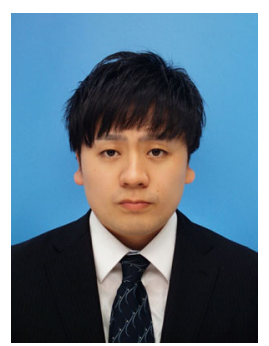

Hirotsuna SATO. He received his B.S., M.S., and Ph.D. degrees in mechanical engineering from Tohoku University, Japan, in 2012, 2014,

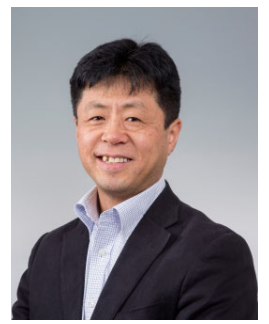

Koshi ADACHI. He graduated in mechanical engineering from Tohoku University in 1988 and obtained his Ph.D. for research in tribology from Tohoku University, Japan, in 1998. He is currently a full professor at the Faculty of Engineering, Tohoku University. He is the head of Laboratory of Tribology and Nanointerface Engineering and director of Center for Tribologically-
Phys 47(1): 013001 (2014)

[38] Li J J, Zhang C H, Sun L, Lu X C, Luo J B. Tribochemistry and superlubricity induced by hydrogen ions. Langmuir 28(45): 15816-15823 (2012)

[39] Li J J, Zhang C H, Deng M M, Luo J B. Reduction of friction stress of ethylene glycol by attached hydrogen ions. Sci Rep 4: 7226 (2015)

[40] Chen M, Kato K, Adachi K. The comparisons of sliding speed and normal load effect on friction coefficients of self-mated $\mathrm{Si}_{3} \mathrm{~N}_{4}$ and $\mathrm{SiC}$ under water lubrication. Tribol Int 35(3): 129-135 (2002)

2020, respectively. His research interests include tribology, nanomaterials, and computational science of multiphysics.

and 2017, respectively. His current position is a researcher of Hino Motors, Ltd. His research areas cover tribology and underlying technologies of diesel engines.

based Machine Design, in Division of Mechanical Engineering, Tohoku University. His research interests span a wide range of tribology, including fundamental and application of tribology, with a particular interest in friction and wear mechanisms of advanced materials, technology for super-low friction, science and technology for running-in control. He is currently challenging to establish new concept named as "Tribologically-based Machine Design" and "Science of running-in". 